\title{
Operating Parameter Optimization using DOE Method to Reduce Unburned Carbon of Fly Ash for Tangential Fired Subcritical Coal Fired Power Plant
}

\author{
Pogganeswaran Gurusingam, ${ }^{1 *}$, Firas Basim Ismail ${ }^{1}$, and Taneshwaren Sundaram ${ }^{1}$ \\ ${ }^{1}$ Power Generation Unit, Institute of Power Engineering (IPE), Universiti Tenaga Nasional, 43000 \\ Kajang, Selangor, Malaysia
}

\begin{abstract}
As electric demand increasing due to rapid economic growth, most developing country are sourcing for cheap fuel and low maintenance power plant which coal fired power plant become the more preferable plant. The cheap and abundant coal resources have played a major factor for coal power plant selection compare to other type of power plant. Although this plant type has low maintenance and operating cost but its emission of by product has a great effect on daily plant operation and environment. The one of the major emission was unburned carbon which by product of incomplete combustion where remaining of coal that unburned exits the furnaces with ash. Presence of higher percentage of unburned carbon indicates the low efficiency of furnace combustion and this directly affects financial status of the power plant operators. This condition causes severe damages on the boiler tube by formation of slagging and clinkering which reduces heat transfer and efficiency of the furnace. Current method proved to be more time consuming and plant operator facing difficulty to reduce unburned carbon in real time. As a solution for this problem, a best parameter was predicted to achieve low percentage of unburned carbon.
\end{abstract}

\section{Introduction}

Coal fired power plant has become Malaysia's largest electric producer with commission of 5 plant in Manjung, Malaysia. Malaysia opted for coal fired power plant due to abundance of coal supplier in South East Asia especially in Indonesia. The cheap and steady coal price contributes for coal fire power plant selection due to lower which operating cost way more cheap than other thermal power plant. As every process, coal fired plant emits few byproducts namely ashes, heat and flue gas. The ashes are by products of coal char burning which produces and separated into two categories which is bottom ash and fly ash. Bottom ash used for ash that dropped into bottom of boiler or hopper and fly ash which flow together with flue gas to furnace outlet. During coal combustion, there is incomplete combustion occurred when unburned carbon remaining mixed with fly ash and exits the furnace. This causes presence of higher percentage of unburned carbon level in fly ash and high amount

${ }^{1}$ Corresponding author: pogganes@gmail.com 
of unburned carbon in fly ash will led more severe issue in power plant operation and affect financially and technically to the operator. Higher unburned carbon percentage in fly ash will lead to environment pollution such as groundwater contamination, air pollution, and respiratory related problem. Meanwhile fly ash is very essential in construction cement manufacturing. Fly ash with lower unburned carbon level is consider as high quality fly ash and improve the strength of concrete and reduces heat of hydration of concrete [1]. As unburned carbon emission in fly ash impossible to eliminate but at least percentage in fly ash needed to be achieved and recommended level of unburned carbon in fly ash estimated need to be around 2-5\% [2] in fly ash. A few method was studied and tried such as usage of infrared light sensor to measure carbon intensity in fly ash [3], Computational Fluid Dynamic (CFD) analysis [4] and combination of ANN with other learning algorithm to forecast the percentage of unburned carbon in fly ash [5]. So, a DOE was carried out to determine the best combination of parameter that can be used to achieve lower percentage of unburned carbon in fly ash. This can be used in plant operation to control parameter to achieve desired parameter in short period of time [6].

\section{Results and discussion}

\subsection{CFD simulation}

A CFD simulation for TNB Janamanjung furnace was modelled to study percentage of unburned carbon in fly ash for particular set of parameter. The furnace contains 28 coal inlets where pulverized coal was injected into furnace. 4 burners were located 1 each at corner of the furnace for each elevation. This furnace contains total 7 elevations. Total 24 burner from 6 elevation used during normal operation while 1 used for back up during any required scenario inlet was located. This simulation was modelled using commercial CFD codes where Fluent was used for species mass fraction, enthalpy and momentum. The furnace was modelled to inject coal size less than 200 micron which is identical used in real operation with primary air and secondary air to simulate combustion. Turbulence viscous model was selected by using standard k- $\varepsilon$ turbulence model. As the model was more than $1 \mathrm{~m}, \mathrm{P} 1$ radiation model was used with Single mixture fraction probability function (PDF) for the coal combustion and heat radiation. Discrete phase model (DPM) was used for coal combustion modelling to solve the transport equations for the continuous phase. Coal combustion started when pulverized coal that injected with air wills it will devolatilize and the coal undergo char combustion where it started to combust when temperature exceeds coal vaporization temperature. Meanwhile the coal diameter was model to follow Rossin- Rammler distribution. In this study, the non-premixed combustion model was used for reaction chemistry. The operating conduction of the furnace is shown in Table 1 meanwhile proximate analysis and ultimate analysis for ADARO coal was tabled in Table 2. ADARO coal composition made of carbon, oxygen, hydrogen, sulphur, and nitrogen which can be obtained from ultimate analysis. The fixed carbon, ash, moisture, and volatile matter for the ADARO coal are obtained from proximate analysis which is shown in Table 2.

Table 1. Operating condition of furnace. 


\begin{tabular}{|c|c|}
\hline Case description & Operating conditions \\
\hline $\begin{array}{c}\text { Total flow rate of total primary air }(\mathrm{km} 3 / \mathrm{h}) \text { and } \\
\text { temperature }(\mathrm{K})\end{array}$ & 600 and $300 \mathrm{~K}$ \\
\hline $\begin{array}{c}\text { Total flow rate of total secondary air }(\mathrm{km} 3 / \mathrm{h}) \text { and } \\
\text { temperature }(\mathrm{K})\end{array}$ & 600 and $550 \mathrm{~K}$ \\
\hline Total coal feed rate $(\mathrm{t} / \mathrm{h})$ & 360 \\
\hline
\end{tabular}

Table 2. Proximate analysis and ultimate analysis of ADARO.

\begin{tabular}{|c|c|}
\hline \multicolumn{2}{|c|}{ Proximate analysis (\%) } \\
\hline Moisture & 40 \\
\hline Ash & 2 \\
\hline Volatile Matter & 37 \\
\hline Fixed Carbon & 34 \\
\hline & \\
\hline Carbon & 69 \\
\hline Hydrogen & 5 \\
\hline Oxygen & 23 \\
\hline Sulphur & 0.1 \\
\hline Nitrogen & 1.4 \\
\hline
\end{tabular}

The simulation used SIMPLE solution approach and a finite volume method was used as most scholars used this method for fossil fuel combustion related simulations. The case was simulated until the simulation achieved the convergence.

\subsection{Validation result}

The simulation was carried out using FLUENT 14.5. The contour plots of temperature can be seen in Fig. 2. The temperature was recorded at 2710k for maximum where it was recorded at bottom of the fireball. The concentration of fuel and air was higher at the burner as high coal and air feed to support the combustion. The temperature decreases as the higher elevation of the furnace due to heat transfer to the wall. When the fuel and air enter the furnace, combustion was occurs due to high velocity and temperature.

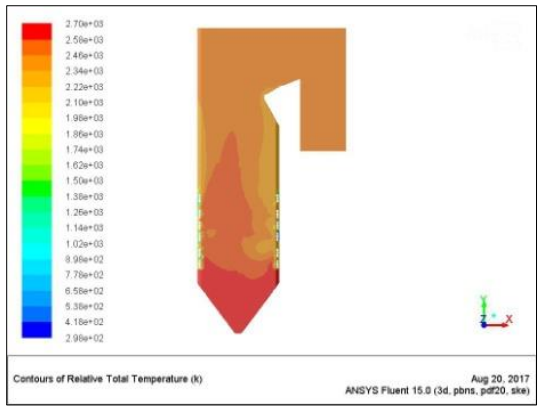

Fig.1. Temperature distribution of coal combustion.

Meanwhile for species distribution from combustion, oxygen and carbon dioxide distribution was obtained and discussed. Fig. 3 and Fig. 4 respectively show the contour plot of oxygen mass fraction and carbon dioxide mass fraction. Higher oxygen concentration was found at burner as air was supplied for combustion and depleted once combustion complete. This explains the lower concentration at higher level of furnace. Meanwhile, the distribution of carbon dioxide mass fraction shows the higher concentration at middle of furnace and having same concentration until exit. This due to carbon dioxide by product of combustion 
thus once combustion completed the concentration was same throughout until it exits the boiler. For unburned carbon level in fly ash, higher concentration was observed at bottom of boiler as this was identified as bottom ash. The figure also shows small dot through the boiler until outlet and this indicate the small amount of Carbon Oxide (CO) in the flue gas.

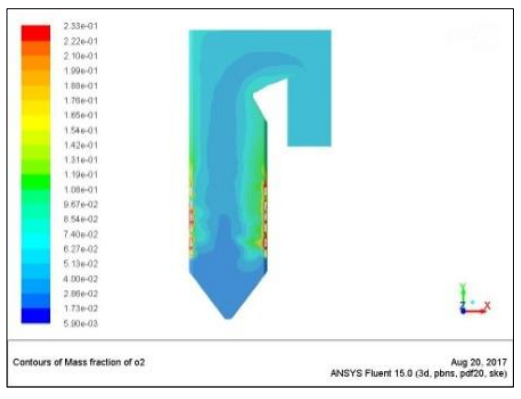

Fig.2. Oxygen mass fraction

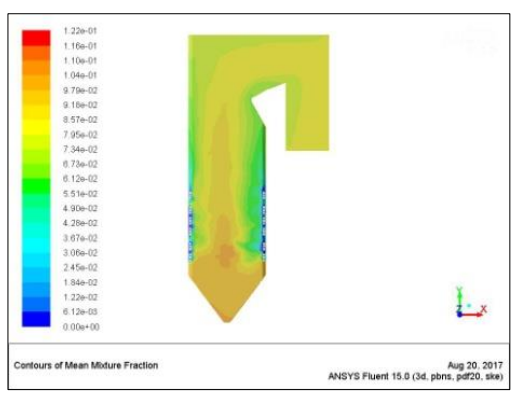

Fig. 4. Carbon Oxide (CO) mass fraction

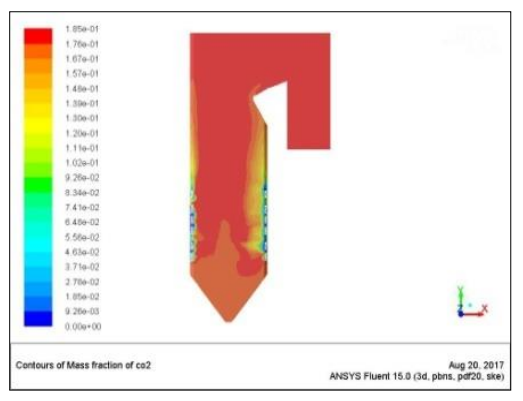

Fig. 3. Carbon dioxide mass fraction

\subsection{DOE result}

For DOE run to find best combination of parameter, four set of parameter was selected which was maximum and minimum of working range. Meanwhile, unburned carbon level and Nox emission level at outlet was kept at output response. The parameter and range was listed in Table 3.

Table 3. Parameters and parameter range

\begin{tabular}{|c|c|}
\hline Parameter & Parameter Range \\
\hline Burner Tilt Position $\left(^{\circ}\right)$ & $-30^{\circ}$ to $30^{\circ}$ \\
\hline RC Feeder Coal Flow $(\mathrm{t} / \mathrm{h})$ & 30 to 60 \\
\hline RH Total Sec Air Flow $(\mathrm{kNm} 3 / \mathrm{h})$ & 500 to 700 \\
\hline LH Total Sec Air Flow $(\mathrm{kNm} 3 / \mathrm{h})$ & 500 to 700 \\
\hline
\end{tabular}

Total 30 run was carried out with 30 possible combination of parameter. Each run will be simulated in CFD to predict the output response which is unburned carbon and Nox emission. The each run output response will be feeded back into DOE table to predict the best combination of parameter which can produce lower level of unburned carbon in fly ash and Nox emission level. The result of simulation run was listed in the table 4 below.

Table 4. Simulation run 


\begin{tabular}{|c|c|c|c|c|c|}
\hline $\begin{array}{l}\text { Burner Tilt } \\
\left.\text { Postion ( }{ }^{\circ}\right)\end{array}$ & $\begin{array}{c}\text { RC Feeder } \\
\text { Coal Flow } \\
(\mathbf{t} / \mathbf{h})\end{array}$ & $\begin{array}{c}\text { RH Total Sec } \\
\text { Air Flow } \\
\text { (kNm3/h) }\end{array}$ & $\begin{array}{c}\text { LH Total Sec } \\
\text { Air Flow } \\
\text { (kNm3/h) }\end{array}$ & $\begin{array}{c}\text { Unburned } \\
\text { Carbon (ppm) }\end{array}$ & $\begin{array}{c}\text { Nox Emission } \\
\text { (ppm) }\end{array}$ \\
\hline 30 & 30 & 700 & 500 & 0.0011 & 0.80 \\
\hline-30 & 60 & 700 & 500 & 0.0032 & 0.68 \\
\hline 30 & 30 & 700 & 700 & 0.0017 & 0.79 \\
\hline-30 & 60 & 500 & 700 & 0.0029 & 0.68 \\
\hline 0 & 45 & 800 & 600 & 0.0014 & 0.50 \\
\hline 0 & 45 & 400 & 600 & 0.0014 & 0.68 \\
\hline 0 & 45 & 600 & 600 & 0.0013 & 0.52 \\
\hline-60 & 45 & 600 & 600 & 0.0023 & 0.77 \\
\hline 30 & 30 & 500 & 500 & 0.0014 & 0.80 \\
\hline-30 & 30 & 500 & 700 & 0.0017 & 0.66 \\
\hline-30 & 30 & 700 & 700 & 0.0025 & 0.72 \\
\hline 0 & 45 & 600 & 600 & 0.0038 & 0.64 \\
\hline 60 & 45 & 600 & 600 & 0.0024 & 0.66 \\
\hline 0 & 45 & 600 & 600 & 0.0042 & 0.75 \\
\hline 30 & 60 & 700 & 700 & 0.0013 & 0.76 \\
\hline 0 & 75 & 600 & 600 & 0.0028 & 0.61 \\
\hline-30 & 30 & 700 & 500 & 0.0023 & 0.77 \\
\hline-30 & 60 & 500 & 500 & 0.0033 & 0.54 \\
\hline 30 & 30 & 500 & 700 & 0.0012 & 0.60 \\
\hline 0 & 15 & 600 & 600 & 0.0044 & 0.53 \\
\hline 0 & 45 & 600 & 600 & 0.0040 & 0.59 \\
\hline 0 & 45 & 600 & 600 & 0.0034 & 0.79 \\
\hline 0 & 45 & 600 & 800 & 0.0047 & 0.65 \\
\hline 0 & 45 & 600 & 600 & 0.0011 & 0.59 \\
\hline-30 & 30 & 500 & 500 & 0.0033 & 0.53 \\
\hline 30 & 60 & 500 & 700 & 0.0018 & 0.73 \\
\hline 30 & 60 & 700 & 500 & 0.0012 & 0.55 \\
\hline 30 & 60 & 500 & 500 & 0.0046 & 0.75 \\
\hline-30 & 60 & 700 & 700 & 0.0017 & 0.67 \\
\hline 0 & 45 & 600 & 400 & 0.0033 & 0.60 \\
\hline
\end{tabular}

From the DOE result, the best set of parameter was at burner tilt angle at $0^{\circ}, \mathrm{RC}$ feeder coal flow at $45(\mathrm{t} / \mathrm{h}), \mathrm{RH}$ total sec air flow at $600 \mathrm{kNm} 3 / \mathrm{h}$ and $\mathrm{LH}$ total sec air flow at 600 $\mathrm{kNm} 3 / \mathrm{h}$. where the predicted unburned carbon ppm at outlet was at 0.002523394 . The predicted data was validated with CFD simulation and the output response was at 0.003238759 . The percentage error shows $28 \%$ percentage error. 
Sub Critical Tangential Coal fired power plant was designed using Fluent 14.5. The output response was validating with existing boiler to validate the model. The model was used to run the simulation for each parameter run to figure the output response. Total 30 run was carried out and the output response was feedback in DOE software to find optimized parameter that can produce lower unburned carbon in fly ash. A set of parameter with predicted unburned carbon level was generate and was validated using CFD .The theoretical value produced by DOE was $0.002523394 \mathrm{ppm}$ and actual value for CFD simulation unburned carbon ppm was 0.003238759 . The percentage difference between theoretical and actual was $28 \%$. The differences were significantly high but this induced from other parameter. Thus more detailed study using more parameter needed to get more accurate result. Thus by using this model, this method can be used to predict the parameter that can produce lower percentage of unburned carbon in fly ash and achieve more sustainable and more environmentally friendly power plant. Thus the objective was achieved by proving a method to optimised parameter to reduced unburned carbon in fly ash.

This work was supported by the TNB Janamanjung Sdn Bhd, Power Generation Research Centre, UNITEN, Universiti Tenaga Nasional and Ministry of Higher Education (MOHE), Malaysia for the opportunity to sponsorship this corresponding research

\section{References}

1. K. S Grochowick, J. Goles, H. Jankowski, Fuel, 83, 1847-1853, (2003)

2. J. Li, R. Jankowski, M. Kotecki, W. Yang, D. Szewczyk, A. Brdekiewicz, W. Blaisk, Energy Fuels, 26, 926-937, (2012)

3. J.M Lee, D.W Kim, J.S Kim, Unburned carbon fraction with operation variables in a commercial circulating fluidized bed during co-combustion of various antarcits, (2011)

4. J.Pallares, I.Arauzo, E.Teruel, Development of an engineering system for unburned carbon prediction, (2008)

5. Z. Hao, X. Qian, K. Cen, J. Fan, Fuel Processing Technology, 85, 113-124, (2003).

6. V. K Srinivasa, S. Renjith, B. Shome, SAE Technical Paper 2014-01-0658, (2014). 